S Kapustka, Lawrence

36 . 7396 Feruttal of

H 2 rarp AECO's reports on

frytotoxicity

(Redente) $\varepsilon$

veetation

STATE OF MONTANA

( Kea $\pi$ merer)

RESOURCE DAMAGE PROGRAM

REBUTTAL OF ARCO'S REPORTS

ON PHYTOTOXICITY (REDENTE) \& VEGETATION (KEAMMERER)

PREPARED BY:

LAWRENCE A. KAPUSTKA Ph.D.

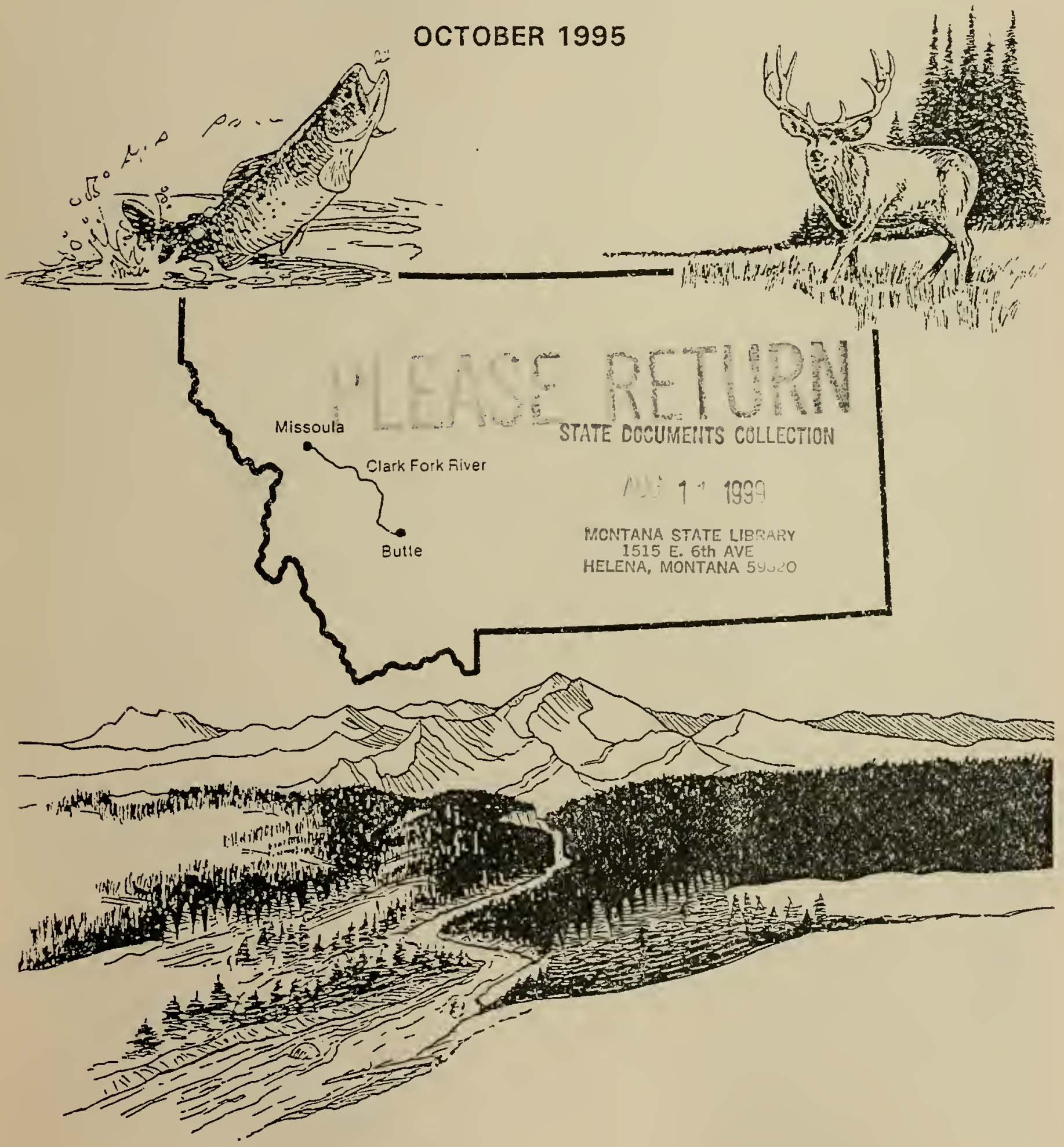




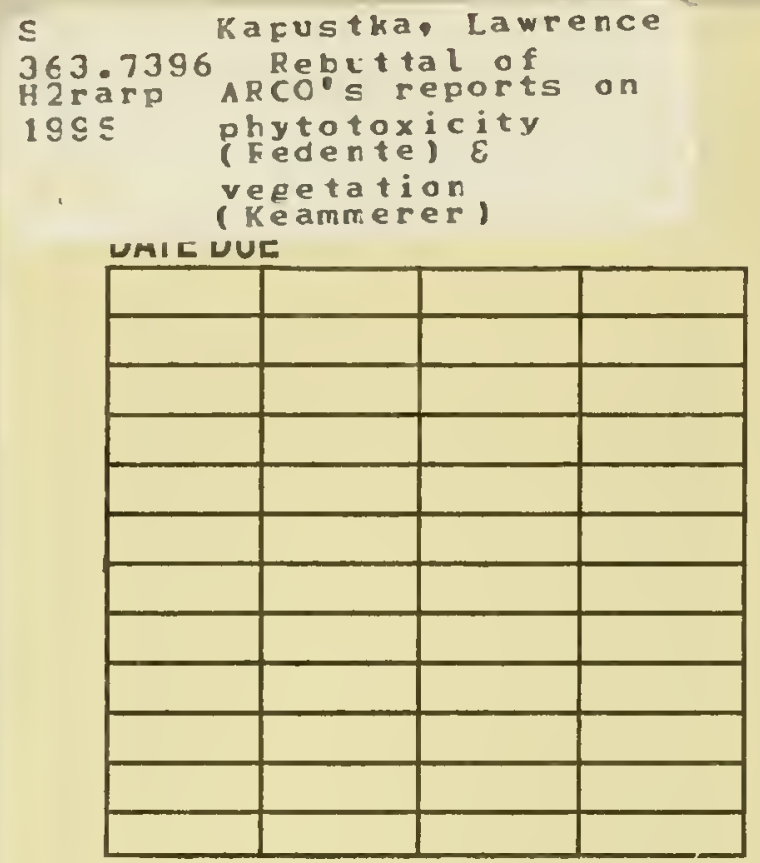

MONTANA STATE LIBRARY

1515 East 6 th Avenue

Helena, MT 59620-1800

\section{AUG 111999}




\section{Rebuttal of ARCO's Reports on Phytotoxicity (Redente) \& Vegetation (Keammerer)}

submitted to

Montana Department of Justice Natural Resource Damage Program

Old Livestock Bidg., 1810 E. Lockey

P.O. Box 201425

Helena, MT 59620

October 1995

by

Lawrence A. Kapustka, Ph.D.

ecological planning and toxicology, inc.

5010 S.W. Hout Street

Corvallis, Oregon USA $97333-9540$

phone: 503/752-3707 FAX: 503/753-9010

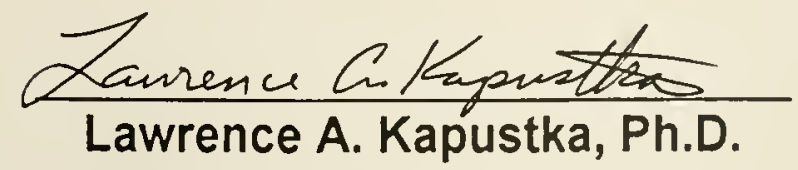




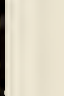




\section{Table of Contents}

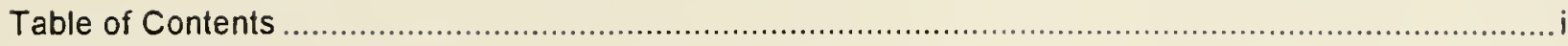

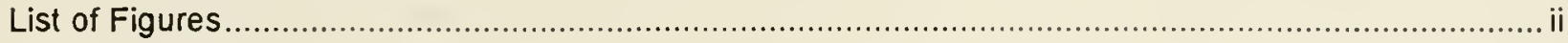

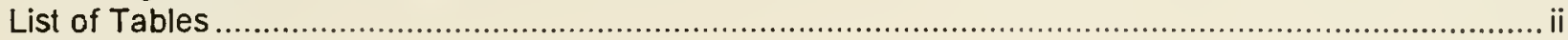

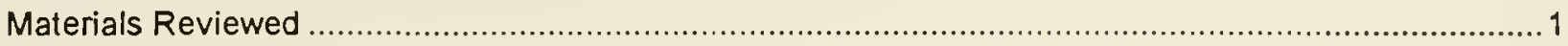

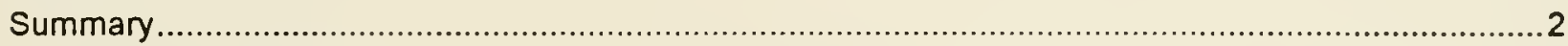

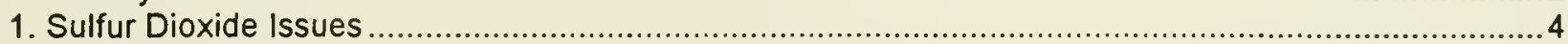

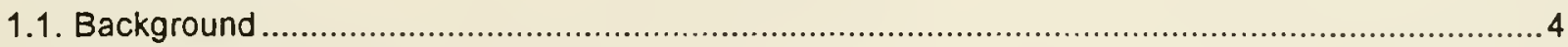

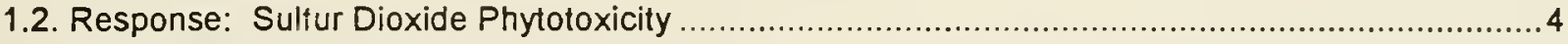

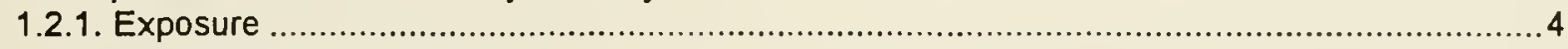

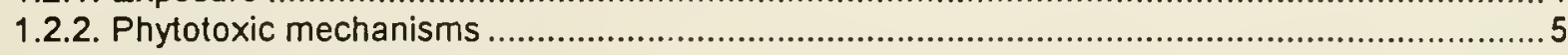

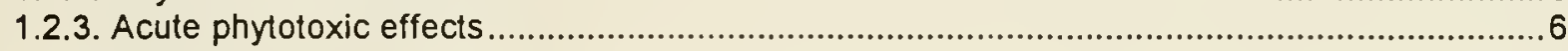

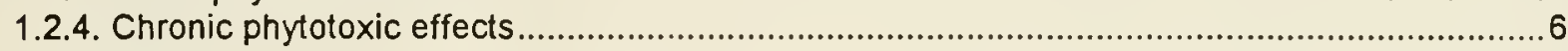

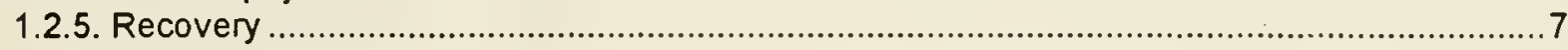

1.2.5.1. Individual plant recovery.........................................................................................

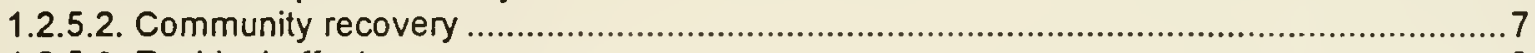

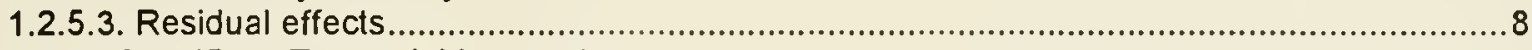

1.3. Issues Specific to Terrestrial Impact Area .................................................................................... 8

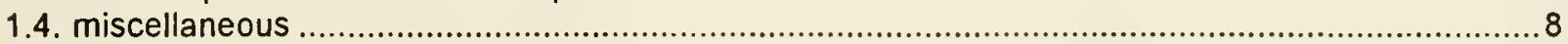

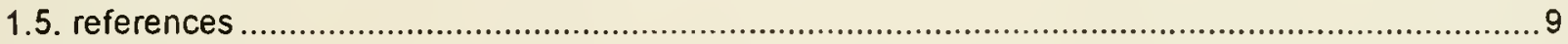

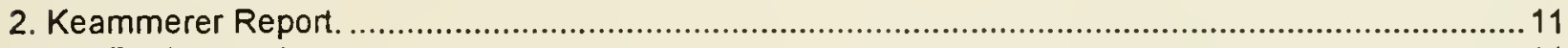

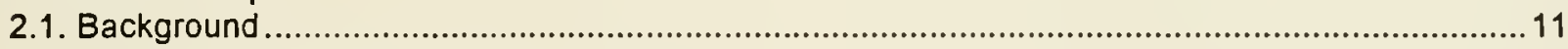

2.2. Critique of the State's Phytotoxicity Study ................................................................................. 11

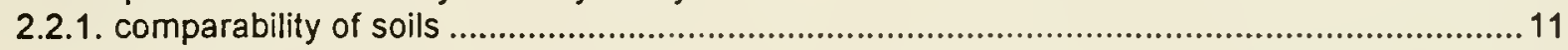

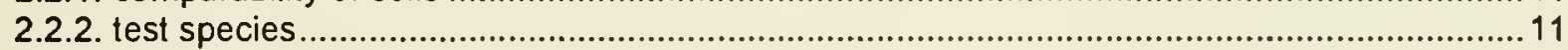

2.2.3. relationship of toxicity to metals ............................................................................................ 11

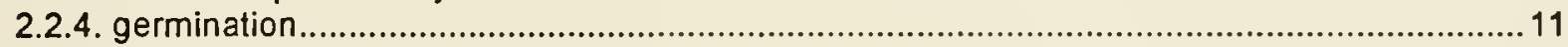

2.2.5. field observations ................................................................................................................ 11

2.2.6. Douglas fir phytotoxicity study ......................................................................................... 12

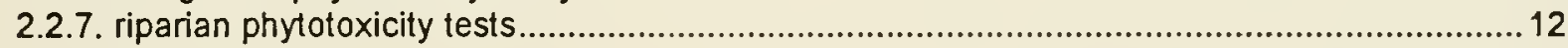

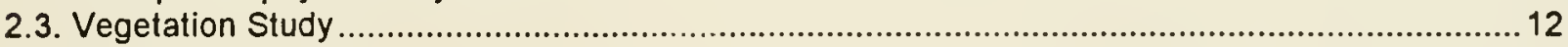

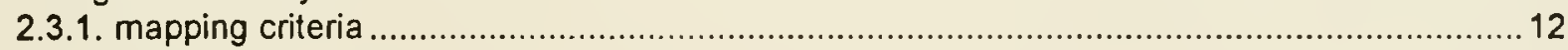

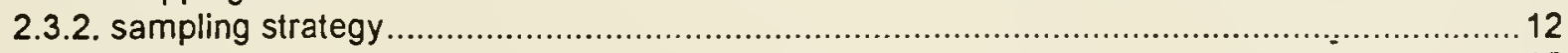

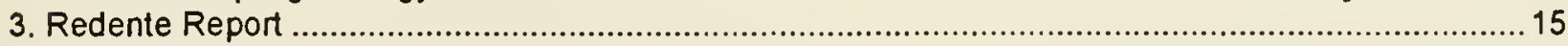

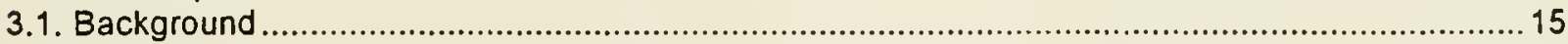

3.2. Criticisms of State's Phytotoxicity Study .............................................................................. 15

3.2.1. Comments on Status of Upland Vegetation ......................................................................... 16

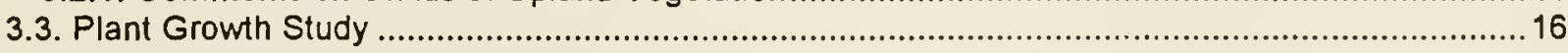

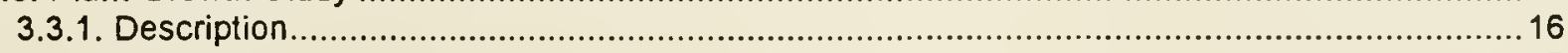

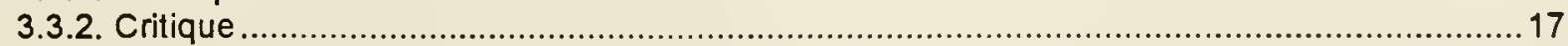


Digitized by the Internet Archive

in 2011 with funding from

Montana State Library

http://www.archive.org/details/rebuttalofarcosr1995kapu 


\section{List of Fiqures}

Figure 1. Average growth of three grasses in German Gulch (GG), Stucky Ridge (SR), and Mt. Haggin $(\mathrm{MH})$ from Redente's study.

\section{List of Tables}

Table 1. Soil available for Redente greenhouse study.............................................................. 17

Table 2. Redente shoot growth (g) for German Gulch (GG), Stucky Ridge (SR), and Mt. Haggin (MH) soil samples. 18

Table 3. Redente root growth (g) for German Gulch (GG), Stucky Ridge (SR), and Mt. Haggin $(\mathrm{MH})$ soil samples.

Table 4. Correlations from Redente Data. 19 
. 


\section{Materials Reviewed}

Copies of reports that were prepared for ARCO were provided by the State of Montana [17 July 1995] for review. The reports were:

1. Redente: Report on Terrestrial Injuries and Restoration (including STARS)

2. Keammerer: Report on Terrestrial Injuries.

Supplemental materials from discovery disclosures by Redente and Keammerer related to their preparation of reports were also supplied for this review.

Earlier reports and background materials related to this case (identified to ARCO prior to and during my deposition) were also examined. In addition, a number of journal articles and books were reviewed to form the supporting base for conclusions and comments presented herein. A complete listing of materials not previously disclosed accompanies this report. 



\section{Summary}

This report is presented in three sections addressing two reports and the sulfur dioxide issue interspersed in their reports. These are:

\section{Sulfur Dioxide Issues}

\section{Redente Report}

\section{Keammerer Report}

Key points developed under each of these sections are summarized below.

Sulfur Dioxide -. ARCO has maintained that the conditions found on the injured areas are due solely to $\mathrm{SO}_{2}$ emissions that killed the vegetation and that subsequent erosion has impeded recovery. ARCO summarily dismisses arsenic and metals as causative agents of the injury.

The literature review undertaken as part of this current review was focused on (a) identifying the mechanism of injury caused by $\mathrm{SO}_{2}$ emissions both at the level of individuals and communities; (b) characterizing the recovery of injured individuals and plant communities; and (c) residual effects in terrestrial systems following $\mathrm{SO}_{2}$ emissions.

The primary long term effects in plant communities around historical smelting sites are caused by soil acidification and metals contamination. After $\mathrm{SO}_{2}$ emissions are reduced, plants rebound to preexposure levels within one to two growing seasons. Communities that were altered by $\mathrm{SO}_{2}$ emissions are likely to begin to recover in a manner similar to any other transient agent (stressor). The only long lasting effect that is somewhat unique to $\mathrm{SO}_{2}$ effects is the acidification of soil. In the terrestrial impact areas (Smelter Hill, Stucky Ridge, Mt. Haggin), soil pH has not dropped to levels that are innately phytotoxic. Therefore, no true residual impacts are attributable to $\mathrm{SO}_{2}$.

Keammerer Report -- Rebuttals to Keammerer's critique of the State's Phytotoxicity study are provided. Many of the challenges to the State's approach and conclusions appear to be based primarily on interpretations of Redente's study. As detailed in the review of Redente's report and supporting materials, rather than contradicting the State's findings, the data strongly support the State's position.

Keammerer's study design relies heavily on maps of the injured areas. The criteria used to prepare the maps are not provided in either the report or the materials disclosed to the State. Working from these maps, Keammerer developed a sampling strategy that had the effect of over-stating the quality of vegetation of the area.

His selection of control areas was based on the vegetation conditions that he was attempting to measure. This violates the fundamental principle of using independent criteria to quality controls.

Because of these nuances of sampling, the quantitative data overstates the quality of vegetation of the impact area throughout his report. Nevertheless, the central descriptions developed in his studies corroborate the findings of the State. If one refers to the percentage cover rather than relative cover, it is clear that $\mathrm{Dr}$. Keammerer is describing areas of very little vegetation. Notwithstanding his claim that the areas are not dominated by noxious weeds, his quantitative data shows high proportions of weeds including those designated as noxious weeds.

Keammerer claims that the poor quality of vegetation of the injured area is due to $\mathrm{SO}_{2}$ emissions. However, none of his data addresses this issue. He relies extensively on the misinterpretations of Redente's study. As summarized above, there is no basis for a residual injury due to $\mathrm{SO}_{2}$. 

Redente Report - Rebuttals to Redente's critique of the State's Phytotoxicity study are provided. Many of the challenges to the State's approach and conclusions appear to be based primarily on interpretations of his own phytotoxicity study. Rather than contradicting the State's findings, his data strongly support the State's position.

Redente used composite samples of soil collected by Keammerer at $0-2$ inches and 2-8 inches from Mt. Haggin, Stucky Ridge, and German Gulch. No soils from Smelter Hill were used. He further composited the soils such that a single $0-2$ inch and 2-8 inch sample was obtained for each area.

Slender wheatgrass, bluebunch wheatgrass, and redtop were used as test species. His analysis and conclusions hinged on comparison among treatments involving amendments with lime, fertilizer, and wood chips, as well as soils from Ft. Collins.

His statistical analyses were inappropriate and the conclusions drawn invalid. First, by including growth results of treatments with Ft. Collins soil, he masked the differences demonstrated among the impact and control soils. Second, failure to include amendment treatments of the control soils, preclude any claims of ruling out toxicity and asserting nutrient limitation as the operative explanation.

A reanalysis of the relevant data [unamended treatments from Mt. Haggin, Stucky Ridge and German Gulch] show phytotoxic results consistent with those reported by the State. Negative correlations of plant growth and soil $\mathrm{As}$ and especially $\mathrm{Cu}$ concentration corroborate the State's findings that linked phytotoxicity to contaminants. 



\section{Sulfur Dioxide Issues \\ 1.1. Background}

ARCO criticizes the State for "ignoring the effects from sulfur dioxide emissions" in its analysis of injury to vegetation. ARCO contend's that no injury has occurred, but then proceeds to argue that all of the adverse effects visited on the vegetation is a result of direct injury to plants by sulfur dioxide $\left(\mathrm{SO}_{2}\right)$ that eliminated vegetation and indirect consequences of erosion. Several general points are raised regarding loss of nutrients, loss of topsoil, and loss of a seed source to effectively reestablish vegetation. ARCO then argues that natural recovery is occurring at a good pace and that nothing further needs to be done to enhance recovery.

\subsection{Response: Sulfur Dioxide Phytotoxicity}

\subsubsection{Exposure}

Sulfur dioxide is one of the five primary emissions from industrial activities. By weight $\mathrm{SO}_{2}$, carbon monoxide, hydrocarbons, particulates and nitrogen oxides are the most abundant industrial emissions, with varying contributions dependent on the type of industry. Smelting operations often emit significant quantities of $\mathrm{SO}_{2}$, along with a variety of particles, typically enriched with metals and metalloids.

Sulfur dioxide emitted during smelter operation is released as a colorless gas that is dispersed by the prevailing winds present at time of generation. Impact to downwind plant communities is largely dependent upon method of introduction to the plants themselves, which is itself controlled by various chemical reactions that occur to the compound in the atmospheric environment. Sulfur dioxide release to atmosphere can be oxidized via a complex series of reactions involving both photolysis and hydrolysis into various sulfite and sulfate compounds. These reactions vary widely due to prevailing $\mathrm{pH}$, temperature and moisture conditions, and also to the presence or absence of other atmospheric chemicals which can act as both catalysts and inhibitors to the reaction process.

Sulfur dioxide that is oxidized in the gaseous phase forms $\mathrm{SO}_{3}$ gas, a highly reactive hydrophilic compound that almost immediately goes into solution with atmospheric water vapor to form sulfuric acid, $\mathrm{H}_{2} \mathrm{SO}_{4}$. This reactive gas can continue to react in the gaseous phase with other chemicals in the atmosphere to form various sulfate compounds. $\mathrm{H}_{2} \mathrm{SO}_{4}$ can also condense into microdroplets available for consolidation into rain drops, and thus be applied to plants and soils in the area, or for direct condensation deposition to plant surfaces and to the soil system. This reaction usually happens within 8 to 48 hours of release (Winner et al., 1985). Repeated long term sulfuric acid deposition has been shown to lead to acidification of soils and surface waters downwind from a variety of $\mathrm{SO}_{2}$ sources (Freedman and Hutchinson, 1980).

Sulfur dioxide can also go directly into solution with water droplets in the air and on plant and soil surfaces, forming sulfite ions via the reaction equilibrium equation:

$$
\mathrm{SO}_{2}+\mathrm{H}_{2} \mathrm{O} \leftrightarrow \mathrm{H}^{+}+\mathrm{HSO}_{3}^{-} \leftrightarrow 2 \mathrm{H}^{+}+\mathrm{SO}_{3}=
$$

Acidic conditions tend to drive the equilibrium towards the production of the $\mathrm{HSO}_{3}{ }^{-}$ion, which has been shown to be the most phytotoxic of these reaction products. Acidic conditions often prevail in plant communities due to the production of humic acid and other naturally occurring organic acids. Also, $\mathrm{SO}_{2}$ can go into solution with water vapor to form sulfite ions, which are then oxidized to form sulfate ions. These reactive ions often then form compounds with other elements contained in particulate matter in the atmosphere.

Due to the many forms into which $\mathrm{SO}_{2}$ gas can be converted, methods of deposition are also diverse. $\mathrm{SO}_{2}$ gas can be directly dry deposited and taken up by plants; in addition, the various sulfite and sulfate ions and ionic compounds can be deposited as particulates or form directly on plant surfaces. Of these 
compounds, it has been demonstrated that the gaseous deposition of $\mathrm{SO}_{2}$ is the most toxic to plants Winner et al., 1985).

\subsubsection{Phytotoxic mechanisms}

As a macronutrient, sulfur causes stimulant effects in low concentrations in plants, and species differ greatly in response to $\mathrm{SO}_{2}$ concentrations in the atmosphere. In more sensitive species and in higher concentrations, $\mathrm{SO}_{2}$ exposure results in direct and indirect phytotoxic effects. Direct effects are caused by deposition on plants or by absorption. Indirect effects result from soil incorporation of sulfur compound and by alteration of nutrient cycling, decomposition and soil chemical reactions.

$\mathrm{SO}_{2}$ uptake from direct deposition on above-ground plant parts is primarily through stomata. As $\mathrm{SO}_{2}$ is absorbed by plant stomata, it dissolves to form $\mathrm{H}_{2} \mathrm{SO}_{3}, \mathrm{HSO}_{3}{ }^{-}$, and $\mathrm{SO}_{3}{ }^{2}$. It is then chemically converted to sulfite and then oxidized to sulfate, the former being more toxic to plants (Ziegler, 1970). The sulfate is either stored or undergoes metabolic conversion to organic forms. Common plant responses to $\mathrm{SO}_{2}$ exposure include increases in free amino acid concentration and enzymes for amino acid metabolism. Higher rates of sulfur uptake and plant tissue sulfur concentrations are correlated with increased plant productivity in wet years and during regrowth following defoliation of plants.

Differential rates of uptake of $\mathrm{SO}_{2}$ among species is theorized to be a function of differences in stomatal resistance, growth rates, position in plant canopies and leaf morphology. For example, low concentrations of $\mathrm{SO}_{2}$ tend to decrease stomatal resistance while higher concentrations may close stomata entirely, but this response is highly dependent on plant species as well as vapor pressure deficit and humidity (Black and Unsworth, 1980; Lauenroth and Preston, 1984). Typical vertical profiles for $\mathrm{SO}_{2}$ gas exist where concentrations are lower near the ground surface compared to $30-60 \mathrm{~cm}$ above the surface (Milchunas and Lauenroth, 1984). Grass species studied exhibited higher tissue concentration of sulfur in the leaf tips and margins, indicating the probability that duration of exposure was the primary factor, due to the older age of these plant parts in the grasses (Hill, 1969). Similarly, coniferous species have a longer duration of exposure due to year round needle presence. However, uptake of $\mathrm{SO}_{2}$ or tissue sulfur concentrations are incomplete measures of the differences in species sensitivity because of species differences in production of sulfur compounds, secondary transport and storage mechanisms, internal morphology and chemical and metabolic pathways. Ability to assimilate $\mathrm{SO}_{2}$ and metabolize it to more benign forms also contributes to differential sensitivity between species.

Jensen and Kozlowski (1975) performed a study on translocation of sulfur from leaves tó below-ground plant parts, exposing four species of deciduous trees to $\mathrm{SO}_{2}$. The most sensitive of the four species to $\mathrm{SO}_{2}$ fumigation, Populus grandidentata (bigtooth aspen), translocated the lowest amount of sulfur to roots. Sugar maple, the least sensitive of the four species, translocated the most sulfur to root parts, illustrating one of the relationships responsible for differing species sensitivity. Kaiser et al. (1993) found pea plants to translocate approximately $55 \%$ of air-borne sulfate from $\mathrm{SO}_{2}$ from leaf parts to roots, with very little excretion from the root systems. In contrast, barley plants retained sulfate from $\mathrm{SO}_{2}$ and no translocation to root parts was observed. Both species exhibited some proton excretion from the roots, and in the pea this appeared to be $\mathrm{SO}_{2}$-dependent, indicating detoxification by oxidation to sulfuric acid from uptake in the leaves of some plants.

Indirect phytotoxic effect mechanisms for $\mathrm{SO}_{2}$ include rainfall deposition, absorption of gas by soils, and mineralization from decomposition of vegetation containing absorbed sulfur from $\mathrm{SO}_{2}$. However, these indirect effects from $\mathrm{SO}_{2}$ are considered to be primarily due to the acidification of soil, which has multiple effects on flora, including decreasing the availability of primary and secondary plant nutrients, increasing availability of some soluble metals, and decreasing nitrogen fixation and helerotrophic potential. These effects can combine to decrease carbon and nutrient turnover (Milchunas and Lauenroth, 1984). 



\subsubsection{Acute phytotoxic effects}

Acute phytotoxic effects are those that most often appear after short duration and high concentration exposure to contaminants. These symptoms would be expected to have relatively rapid onset after exposure and are most often visually apparent. The severity of symptoms vary widely from species to species, with some species exhibiting sensitivity and others exhibiting resistance, and are generally concentration dependent. Some plant species, however, exhibit wide response variability at similar exposure levels at the genotype level (McLeod and Skeffington, 1995). $\mathrm{SO}_{2}$ studies have been conducted whereby limited numbers of species, and often a single species, are exposed to levels of $\mathrm{SO}_{2}$ many times higher than vegetation would be expected to receive in all but worst case, short duration releases. Exposure levels at concentrations producing acute effects are normally of a short time duration as the phytotoxic effects of high concentration levels have been demonstrated to range up to total plant community destruction (Freedman, 1980; Kozlowski, 1985).

Acute symptoms documented usually encompass foliage damage characteristics including chlorosis (Peiser and Yang, 1985), marginal and intercostal necrosis for broad-leaved plants (Treshow and Anderson, 1989) and needle tip necrosis and necrotic banding for coniferous trees. (Leininger et al., 1991) One study observed needle necrosis affecting some specimens of Pinus sylvestris (Scots pine) to such an extent that nearly all current year needles were damage extensively and shed within four months following bud burst. (Holland et al., 1995) If exposures leading to such acute symptom expression - i.e. long duration at high $\mathrm{SO}_{2}$ concentrations - are continued, plant death, species decline and ecosystem alterations have been shown to occur in coniferous communities (Kozlowski, 1985) and in broad-leaved communities (Steubing and Fangmeier, 1987).

\subsubsection{Chronic phytotoxic effects}

Chronic phytotoxic effects are those that appear after long duration and lower concentration exposure to contaminants. These symptoms would demonstrate themselves after long exposure to low concentrations of $\mathrm{SO}_{2}$ and are more subtle nature than acute symptoms. Often times these negative effects become apparent only above a species specific threshold concentration or after long term exposure; below these thresholds, the nutrient supplying properties of $\mathrm{SO}_{2}$ may positively impact the test species. (Lauenroth and Preston, 1984). Extensive research has been performed using long duration exposure at low concentration levels in attempts to mimic field conditions expected to be encountered in an impacted natural ecosystem. The most common method of exposure for these studies has been computer controlled $\mathrm{SO}_{2}$ fumigation systems, both in open field experiments and in open and closed type chamber studies (Lauenroth and Preston, 1984, McLeod, 1985 as cited in McLeod and Skeffington, 1995; Winner et al., 1985).

Chronic symptoms observed include variation in live and dead leaf area, stem diameter, and plant heights (Garsed et al., 1979); variations in production of above and below ground biomass (Lauenroth and Preston, 1984); accelerated leaf aging and variation in time of leaf fall (Mohren et al., 1992); and variations in such physiological parameters as chlorophyll production and membrane damage, sulfur partitioning, carbon utilization and stomatal response. It should be noted that in many studies addressing $\mathrm{SO}_{2}$ impact to plants as a stand alone contaminant, the chronic effects of $\mathrm{SO}_{2}$ documented have varied widely, both between species, and also between individual genotypes within a species. (Leininger et al., 1991; McLeod and Skeffington 1995)

Some studies have demonstrated $\mathrm{SO}_{2}$ resistance within herbaceous species after long-term exposure (Bell, 1985; Westman et al., 1985). Other studies noted little significant $\mathrm{SO}_{2}$ damage at lower ambient concentrations for some species along with mild increases in overall productivity due to nutrient enrichment caused by sulfur enhancement and co-deposition of $\mathrm{N}$-bearing compounds from the atmosphere (McLeod and Skeffington, 1995). Still another study noted an increased phytotoxic response 

to broadleaf trees and grasses when exposed to lower levels of mixed $\mathrm{SO}_{2} / \mathrm{NO}_{2}$ gases (Whitmore, 1985). Garsed et al. (1979) found that while the broad-leaved trees used in their study demonstrated some chronic effects, such as minor variations in dry leaf weight and mean leaf area, no reductions in dry matter production or visible symptoms were found at exposure levels that caused significant growth depression to a coniferous species.

\subsubsection{Recovery}

The recovery of plants after $\mathrm{SO}_{2}$ exposure has stopped can be looked at from the level of individual plants as well as at the community level. On the individual level, some effects are reversible and others are not, depending on the magnitude of exposure. Due to the length of time involved, it is more difficult to determine the effects of $\mathrm{SO}_{2}$ exposure on plant communities

\subsubsection{Individual plant recovery}

Some of the damage caused by $\mathrm{SO}_{2}$ exposure is reversible. Decline in gas exchange capacity necessary for photosynthesis due to stomatal closure during fumigation is reversed within minutes or hours, depending on the species involved, after levels of $\mathrm{SO}_{2}$ drop (Steubing and Fangmeier, 1987). Photosynthesis can also be reduced due to toxic build-ups of sulfite within plant tissues, but effect is reversible as long as the rate of build-up does not exceed the plant's capacity to detoxify it (Mohren et al., 1992). Holland et al. (1995) noted that abnormal shoot extension growth in $\mathrm{SO}_{2}$ fumigated Picea sitchensis (Sitka spruce) trees returned to normal the year after fumigation ceased.

Individual plant recovery has also been noted under field conditions. Cores taken from Pinus contorta (lodgepole pine) growing $14.5 \mathrm{~km}$ north of a smelter at Trail, British Columbia exhibited decreased growth between the years of 1919 and 1945, corresponding with the greatest emissions from the smelter. After the emissions stopped, growth rate increased to pre-exposure levels (Archibold, 1978).

Certain acute types of damage, such as tissue damage and foliage loss leading to plant death are irreversible. In addition, extended exposure to $\mathrm{SO}_{2}$ can reduce a plant's ability to survive other stresses such as drought and extreme weather conditions (Tesche, 1992).

\subsubsection{Community recovery}

Recovery at the community level is a complicated issue. Initial damage, differences in individual plant tolerance to $\mathrm{SO}_{2}$, differences in species tolerance to $\mathrm{SO}_{2}$, and the regenerative abilities of each plant species all affect community recovery. The damage caused by $\mathrm{SO}_{2}$ emissions from a smelter varies throughout a region based on distance from the smelter and weather patterns at the time of release.

Damage can range from hilltops denuded of vegetation with soils eroded and bedrock blackened from $\mathrm{SO}_{2}$ and sulfuric acid mist (Freedman and Hutchinson, 1980), to areas with some species damage, to areas with little or no damage farthest away from the smelter. In areas of severe damage, lack of seed source has been cited as the major problem inhibiting regeneration (Archibold, 1978.) It has also been suggested that community regeneration around smelters has been inhibited by heavy metals in the soils (Freedman and Hutchinson, 1980) and by a disruption in nutrient flow due to an absence of decomposers (Walsh and Bissel, 1979).

Due to differences in resilience between different plant species, it is likely that there will be changes in community composition as a result of $\mathrm{SO}_{2}$ emissions. Extremely sensitive plant species can be expected to be eliminated entirely. Steubing and Fangmeier (1987) found that the structure of the herb layer of beech forests could be severely modified by $\mathrm{SO}_{2}$ application. Freedman and Hutchinson(1980) has noticed a simplification of communities in areas damaged by $\mathrm{SO}_{2}$. 



\subsubsection{Residual effects}

Residual effects in soil predominately include effects and processes from the secondary products of $\mathrm{SO}_{2}$ fumigation. Lowered $\mathrm{pH}$ and lowered cation exchange capacity as a result of acid rain and soil acidification reduces nutrient availability. Metals in soils may become more or less bioavailable to plant species due to lowered $\mathrm{pH}$ from past effects of $\mathrm{SO}_{2}$ reaction product deposition. Personal communication with researchers formerly engaged in $\mathrm{SO}_{2}$ studies indicate that the primary long term effects in plant communities around historical smelting sites are caused by soil acidification and metals contamination. Erosion due to lack of vegetation and organic matter can inhibit community recovery, and the possible loss of seed stock can complicate regeneration of plant communities. Erosion, regardless of acid deposition, tends to increase acidity (i.e., lower $\mathrm{pH}$ ) of soils. Further personal communications with researchers also indicated that although ecosystem recovery after termination of $\mathrm{SO}_{2}$ emissions was of interest to many, funding sources were never located for such studies. None of the individuals contacted could cite a single study that followed the recovery of plant communities after $\mathrm{SO}_{2}$ emissions were curtailed.

Dr. Robert Goldstein (EPRI) responding to questions in a telephone conversation indicated that EPRI has not published nor done extensive research on ecosystem recovery to $\mathrm{SO}_{2}$ impact. He further stated that the major impact from $\mathrm{SO}_{2}$ emitted by power generation facilities is reduced crop production and declines in plant biomass. After $\mathrm{SO}_{2}$ emissions are reduced, plants rebound to pre-exposure levels within one to two growing seasons.

\subsection{Issues Specific to Terrestrial Impact Area}

The key points identified in the vast body of research indicates that $\mathrm{SO}_{2}$ can have severe direct phytotoxic effects. Upon relief from exposure, individual plants that have survived, recover relatively quickly. Communities that were altered by $\mathrm{SO}_{2}$ emissions are likely to begin to recover in a manner similar to any other transient agent (stressor). The only long lasting effect that is somewhat unique to $\mathrm{SO}_{2}$ effects is the acidification of soil. In the terrestrial impact areas (Smelter Hill, Stucky Ridge, Mt. Haggin), soil pH has not dropped to levels that are innately phytotoxic. Therefore, no true residual impacts are attributable to $\mathrm{SO}_{2}$.

Unquestionably, the impact areas have experienced considerable wind and water erosion that has removed top soil. Despite the level of surficial erosion, the current soil surface layers retain bioavailable metals at concentrations that are phytotoxic as evidenced by laboratory tests conducted by the State and by ARCO. Surely, the lowering of $\mathrm{pH}$ that may be attributable to $\mathrm{SO}_{2}$ emissions exacerbates the phytotoxic situation. Nevertheless, the levels of surface contaminants continue to restrict the esiablishment and development of vegetation communities.

ARCO claims the loss of top soil and the absence of seed sources are the controlling factors. However, mere removal of top soil, even to the $C$ horizon, is not sufficient to stop plant colonization. Witness the rapid regrowth of tree, shrub, and herbaceous cover along roadsides where all soil is removed during construction. A restriction of seed source could explain the absence of some species. However, seed dispersal provides long-range dispersal (many kilometers) for many species. In Montana, winter winds and frozen (snow-covered) surfaces enable many seeds to move relatively unimpeded across great distances. In his report on experiments conducted at Bunker Hill, Idaho, Dr. Redente commented that during the second year, many plants colonized his plots. His plots were quite some distance from established plant communities, suggesting that long-range dispersal was operating.

\section{4. miscellaneous}

Redente's disclosures included an undated report from Michael Treshow [RED000000404-414] entitled "Sulfur Dioxide Effects: A Brief Review of its History as a Phytotoxicant, Symptoms of Injury, Plant Sensitivity, Physiological and Biochemical Mechanisms, Plant Growth and Production Recovery." The latest reference cited is 1989 . Nevertheless, Treshow refers to Russia rather than the Soviet Union. He also repeatedly refers to Eastmond (1971). His characterization of Eastmond is slanted toward sulfur emissions, which were only a part of Eastmond's focus. The characterization of the vegetation condition 

related to the Garfield Smelter grossly misrepresents a series of reports by individuals from Utah State University and Stanford Research Institute who studied the same area. Moreover, the flavor of Treshow's commentary is decidedly different than what was found in more recent studies of that area.

\section{5. references}

1. Archibold, O.W. 1978. Vegetation recovery following pollution control at Trail, British Columbia. Can. J. Bot., 56:1625-1637.

2. Bell, J. N. B. 1985. $\mathrm{SO}_{2}$ Effects on the Productivity of Grass Species; pp $209-226$; as contained in Winner, W. E., H. A. Mooney, R. A. Goldstein (eds.); Sulfur Dioxide and Vegetation: Physiology, Ecology, and Policy Issues. Stanford University Press, Stanford, California.

3. Black, U. J., and M. H. Unsworth. 1980. Stomatal responses to sulfur dioxide and vapor pressure deficit. J. Exp. Bot., 31:667-677.

4. Eastmond, R. 1971. Response of four plant communities to eroded soils and smelter smoke in Northern Utah. Ph.D. Dissertation. University of Utah. Salt Lake City, UT

5. Freedman, B., and T. C. Hutchinson. 1980. Long-term effects of smelter pollution at Sudbury, Ontario, on forest community composition. Can. J. Bot., 58:2123-2140.

6. Garsed, S. G., J. F. Farrar, and A. J. Rutter. 1979. The effects of low concentrations of sulphur dioxide on the growth of four broad-leaved tree species. J. Applied Ecology, 16:217-226.

7. Hill, A. C. 1969. Air quality standards for fluoride vegetation effects. J. Air Pollut. Control Assoc., 19:331-336.

8. Holland, M. R., P. W. Mueller, A. J. Rutter, and P. J. A. Shaw. 1995. Growth of coniferous trees exposed to $\mathrm{SO}_{2}$ and $\mathrm{O}_{3}$ using an open-air fumigation system. Plant, Cell and Environment, 18:227-236.

9. Jensen, K. F., and T. T. Kozlowski. 1975. Absorption and translocation of sulfur dioxide by seedlings of four forest tree species. J. Environ. Qual., 4:379-382.

10. Kaiser, W. M., M. Höfler, and U. Heber. 1993. Can plants exposed to $\mathrm{SO}_{2}$ excrete sulfuric acid through the roots? Physiol. Plant., 87:61-67.

11. Kozlowski, T. T. $1985 . \mathrm{SO}_{2}$ Effects on plant Community Structure; pp $431-453$; contained in Winner, W. E., H. A. Mooney, R. A. Goldstein (eds.); Sulfur Dioxide and Vegetation: Physiology, Ecology, and Policy /ssues. Stanford University Press, Stanford, California.

12. Lauenioth, W. K. and E. M. Preston. 1984. The Effects of $\mathrm{SO}_{2}$ on a Grassland: A Case Study in the Northern Great Plains of the United States. Springer-Verlag, New York.

13. Leininger, T. D., P. R. Miller, S. L. Schilling, and P. H. Dunn. 1991. Seedling responses of five species of western conifers to simulated ambient sulfur dioxide exposures. For. Sci, 37(6):1538-1549.

14. McLeod, A. R., and R. A. Skeffington. 1995. The Liphook forest fumigation project: an overview. Plant, Cell and Environment, 18:327-335.

15. Mohren, G. M. J., I. T. M. Jorritsma, A. W. M. Vermetten, M. J. Kropff, W. L. M. Smeets, and A. Tiktak. 1992. Quantifying the direct effects of $\mathrm{SO}_{2}$ and $\mathrm{O}_{3}$ on forest growth. For. Ecol. Manage., 51:137-150.

16. Peiser, G. and S. F. Yang. 1985. Biochemical and Physiological Effect of $\mathrm{SO}_{2}$ on Nonphotosynthetic Processes in Plants; Pp. 148 - 161; as contained in Winner, W. E., H. A. Mooney, R. A. Goldstein (eds.); Sulfur Dioxide and Vegetation: Physiology, Ecology, and Policy Issues. Stanford University Press, Stanford, California, 1985.

17. Steubing, L., and A. Fangmeier. 1987. $\mathrm{SO}_{2}$-sensitivity of plant communities in a beech forest. Environ. Pollut., 44:297-306.

18. Tesche, M. 1992. Immediate and long-term (memory) responses of Picea abies to a single growing season of $\mathrm{SO}_{2}$-exposure or moderate drought. For. Ecol. Manage., 51:179-186.

19. Treshow, M., F. K. Anderson. 1989. Plant Stress from Air Pollution. John Wiley \& Sons, New York, New York, 269 pp.

20. Walsh, N. and $G$. Bissell. 1979. Impact of copper smelter emissions on two subalpine ecosystems near Anaconda, Montana. Northern Region USDA Forest Service Publication. Report No 79-7. 

21. Westman, W. E., K. P. Presto, and L. B. Weeks. 1985. SO Effects on the Growth of Native Plants; pp. 264 280; as contained in Winner, W. E., H. A. Mooney, R. A. Goldstein (eds.); Sulfur Dioxide and Vegetation: Physiology, Ecology, and Policy /ssues. Stanford University Press, Stanford, California.

22. Whitmore, M. E. 1985. Effects of $\mathrm{SO}_{2}$ and $\mathrm{O}_{3}$ on Plants; pp. $296-312$; as contained in Winner, W. E., H. A. Mooney, R. A. Goldstein (eds.); Sulfur Dioxide and Vegetation: Physiology, Ecology, and Policy Issues. Stanford University Press, Stanford, California.

23. Winner, W. E., H. A. Mooney, R. A. Goldstein 1985. Sulfur Dioxide and Vegetation: Physiology, Ecology, and Policy Issues. Stanford University Press, Stanford, California, $520 \mathrm{pp}$

24. Ziegler, I. 1975. The effect of $\mathrm{SO}_{2}$ pollution on plant metabolism. Residue Review, 56:79-105. 



\section{Keammerer Report. \\ 2.1. Background}

ARCO contends that although no injury has occurred, the vast areas that were devastated by smelter emissions are recovering rapidly and without human intervention. Dr. Warren Keammerer has conducted a survey of vegetation (from 1993 to 1994) of the impacted areas and reported on upland and riparian areas.

Dr. Keammerer relies on Dr. Redente's conclusions and Dr. Redente relies on Dr. Keammerer's conclusions. It appears, however, that neither relies on the data they generated in their respective studies.

\subsection{Critique of the State's Phytotoxicity Study}

\subsection{1. comparability of soils}

The emphasis of this critique is two-fold: organic matter and nutrient differences that might exist from the control soils and the eroded impact areas. The State acknowledged differences in organic matter among the control and impact soils, but also demonstrated comparability in nutrient content. However, the operative difference was the concentrations of arsenic and metals. The soil metal and arsenic concentrations remain the primary controlling factor that has and continues to preclude development of functional plant communities in the impact area.

\subsection{2. test species}

The State has justified the selection of test species in terms of the widely accepted phytotoxicity testing standards. Keammerer's assertion that annual grasses and annual forbs are irrelevant to the plant communities of the impact area is unfounded. His further comment that Redente's study showed no differences in growth for native and introduced species from Stucky Ridge, Mt. Haggin, and German Gulch derives only from Redente's conclusions inappropriately drawn from a limiting study design and statistical analysis. Redente's data does show reduced plant growth in the impact area soils compared to the German Gulch control soils similar to the results of the State. Though such information was not required to justify the State's use of test species, Redente's study corroborates that the choice of species was reasonable and valid.

\subsection{3. relationship of toxicity to metals}

The relationship among phytotoxic response and contaminant concentration was established by the State through correlations as presented in its reports. The argument raised by Keammerer merely combines his earlier points where he showed concern over the comparability of soils, the test species used, and Redente's results. Since none of his arguments hold individually, they cannot hold collectively.

\subsection{4. germination}

Germination was scored and reported by the State. As is often the case with germination, it is not a particularly sensitive endpoint. Nevertheless the data was incorporated in the analysis. In the cases where germination in control soils was low, the likelihood of demonstrating a difference among treatments is greatly diminished. Even so, the State showed a range of toxicity from mild to severe. Mortality was largely accounted for in the germination (or more properly emergence) percentage, in that those seedlings that died before breaking through the soil surface were counted as un-germinated seeds.

\subsection{5. field observations}

The State did not ignore the field observations. The information was included in considering the restoration plans, especially the importance of establishing plants below the surface layer of the most contaminated soil. 



\subsubsection{Douglas fir phytotoxicity study}

It is not correct to claim that the information was ignored. As described in the State's report and background materials, logistical problems related to getting the soils delayed the start of the test such that the seedlings had completed growth for the year. Since insufficient growth occurred during the test, the test was invalid. No useful information could be derived from it either to support or refute a phytotoxicity hypothesis.

\subsection{7. riparian phytotoxicity tests}

The charge is erroneous. The fact that the test soils had low $\mathrm{pH}$ values does not invalidate conclusions of phytotoxicity. Some of the pH values were so low as to constitute evidence of injury without tests. The combination of low $\mathrm{pH}$ and high metal concentrations resulted in laboratory phytotoxicity. The tests and the interpretation presented by the State are valid.

\subsection{Vegetation Study}

\subsection{1. mapping criteria}

The heart of Dr. Keammerer's study design lies with the vegetation mapping he prepared for the impact area. He recognized the following mappable units:

- aspen woodlands

- coniferous forest

- forb/grassland

- bare areas

- meadows

- willow shrublands

Nowhere in his report or in the papers provided to the State does he describe the mapping criteria used to discriminate among these "types." Mapping requires explicit definitions of each mappable unit. This includes physical and biological structural features. The biological structural features should pertain to quantitative or qualitative ranges of cover or abundance of dominant plant taxa or lifeforms and an indication of resolution.

It appears that Dr. Keammerer partially adopted an approach based on the potential vegetation of the area rather than a description of extant conditions. The potential vegetation concept is useful to describe baseline conditions, but for site-specific studies the approach is misleading in that it suggests a more robust vegetation is present. Alternatively, he used an uncommonly loose definition of what constituted a vegetation type. Having observed the areas and examined the sampling data, I conclude that Dr. Keammerer has been exceedingly generous in the interpretation of vegetation types used to produce his maps.

\subsection{2. sampling strategy}

No coherent description of the sampling strategy was presented in the report or accompanying materials. The most troubling part of the limited description was on page 24 of Keammerer's report, "Sampling points were located in the dominant vegetation type in the randomly chosen cells." First, the mapping criteria are suspect or non-existent as noted above. But then, instead of relying on a randomly chosen point, he apparently biased his sampling by subjectively positioning his plot within the "expected vegetation type" of the area. It is not clear whether his subjective positioning of sample locations was done from the photographs before going to the field or if he did this once he was in the field. Either way, this created and uncorrectable bias that invalidates the sample results. A literal interpretation of this strategy is that if the area was mapped as "bare" he would select the barest area of the sample area; if 

grassland, he would select the best representation of grassland in the sample area -- all disregarding the general nature of the plot or the larger sampling unit. This procedure invalidates all conclusions that were made by Keammerer concerning the impacted areas, because not all sites in the impact area are potentially present in his study. Only sites meeting the requirement of being in the subjectively judged "dominant vegetation type" could be included. Other sites representing edge effects, small patches, or barren ground in so called vegetated areas were effectively eliminated from the study and represent a bias that cannot be corrected.

A key feature of his comparisons depends on his selection of reference areas. Nowhere in his report or in the accompanying disclosed information, does Dr. Keammerer describe the selection criteria for reference areas. Surely, if he looked for equally devegetated areas to make his comparisons, he should get close agreement regarding cover. However, the point of selecting a reference is to rely on independent criteria; not the very endpoints to be measured. The State elected to use elevation, slope, aspect, history of disturbance as evidenced by roads, logging, grazing, fire, etc. to qualify reference locations. The State's approach permits a legitimate comparison of plant community endpoints. Keammerer's apparent approach was to find a bare area to compare with a bare area; the ultimate conclusion he derived was that he could identify bare areas that were approximately similar. His approach forecloses any opportunity to make the comparisons asked for in the NRDA regulations, and does not constitute a rebuttal of the State's injury determination.

The point sampling routine employed in Keammerer's study is especially well suited for sparsely vegetated areas or ones with low-growing lifeforms. The underlying premise of the sampling scheme is that the point (in this case crosshair) is a dimensionless locus. If properly sighted, (i.e., free from positional bias), the likelihood of the point being situated on rock, soil, litter, or a particular plant is proportional to the distribution of that observable unit in the sample area. Operating this sampling technique, perhaps more than most sampling methods, requires extreme care to avoid bias. The strong, unintentional urge is to "expand" the point so that additional taxa are added to the sample; more litter, more cover of certain taxa, etc. ase scored. The physical space defining the intersection of the crosshair, though theoretically occupying no area, in practice may be a quarter to one-half $\mathrm{mm}^{2}$. Allowing this to expand slightly, or allowing wind-swept plant parts to be counted as they sway across the point, dramatically alters the quantitative data scored. The difficulty of maintaining objectivity during sampling can only be addressed through rigorous Quality Control steps, including such activities as repeated sampling of plots and comparisons among technicians. Apparently, such steps were not included. Consequently, precision and accuracy of sampling is unknown. One can assume, however, that the cumulative sampling errors in this method limit the value of the data 10 gross descriptions of patterns rather than fine details.

Given the high frequency of one-time species "hits," further calls into question the fortuitous sampling. Sampling routines of this nature are effective in quantifying the dominant cover type. They are decidedly poor at identifying rare or low occurrence taxa. The method would be most effective in determining the percentage rock, gravel, and soil in the impact areas, and progressively less accurate in characterizing the sparse plant cover. Referring to just the plants identified in Table A-1 pages $214-231$, nearly $60 \%$ were listed as $<1$. Since 100 points were scored for each sample location, each hit represents $1 \%$ cover, this large number of entries apparently represent plants identified in the sample area but not in the sample. Only a few sample locations out of the 70 locations sampled on Stucky Ridge had a "dominant species $^{n}$ in the sample, [e.g., only $4 \%$ of the samples had a taxon with $>15 \%$ cover and only $14 \%$ had cover $>5 \%$ ]. Of the "dominant" taxa, Circium arvense had $>5 \%$ cover in 18 of the 70 plots; Centaurea maculosa had $>5 \%$ cover in 11 of the 70 plots; Elymus cinerus and Agrostis alba had $>5 \%$ in 11 of 70 and 9 of 70 respectively. A cursory look at the data sheet summaries for Mt. Haggin and German Gulch suggests a similar picture, especially regarding the number of " $<1^{n}$ entries.

Dr. Keammerer defined trees as $\geq 2$ inches diameter at breast height (dbh). Typically, trees are defined as $\geq 4$ inches $\mathrm{dbh}$ or even $\geq 5$ inches $\mathrm{dbh}$. Survivorship of saplings (i.e., 2 -inch $\mathrm{dbh}$ ) is typically low such that $50 \%$ or more of the 2 - inch dbh trees will die before reaching 4 -inches $\mathrm{dbh}$; this under favorable conditions -- in high stress areas survival may be considerably less. 

Throughout his report, because of these nuances of sampling, the quantitative data overstates the quality of vegetation of the impact area. Nevertheless, the central descriptions developed in his studies corroborate the findings of the State. If one refers to the percentage cover (not the relative cover), it is clear that Dr. Keammerer is describing areas of very little vegetation. Notwithstanding his claim that the areas are not dominated by noxious weeds, his quantitative data shows high proportions of weeds including those designated as noxious weeds.

Keammerer's data as presented in Table 45 shows significantly lower concentrations in his control soils than in Stuck Ridge and/or Mt. Haggin for $\mathrm{As}, \mathrm{Cd}, \mathrm{Cu}$, and $\mathrm{Pb}$. The sampling design, being based on the poorly described vegetation mapping types and a biased site selection process, makes it impractical and invalid to draw conclusions regarding differences that may or may not exist across "vegetation types."

In the body of his report, Dr. Keammerer draws on the oft used $\mathrm{SO}_{2}$ scenario as an explanation for the depauperate vegetation. None of his data speaks to this issue. He attempts to draw in the results of Redente's study as supportive evidence. However, as detailed in my critique of Redente's study, his study design was incapable of addressing causal relationships. Moreover, Redente's data are consistent with the State's phytotoxicity studies in showing reduced growth of shoots, and roots of three relatively hardy grass species. As argued by the State, neither the $\mathrm{SO}_{2}$ scenario [nor any other agent (logging, fire, grazing, etc.)] can account for the laboratory phytotoxicity of current soils or the depauperate vegetation condition observed on the site and documented in Keammerer's study.

ecological planning and toxicology, inc.

October 1995

Page 14 



\section{Redente Report}

\subsection{Background}

Dr. Redente criticized the State's phytotoxicity study for:

- "failure to establish that the soils are toxic to native plants,"

- "failure to link endpoints to metal concentrations,"

- "modifications of ASTM procedures that undermine the validity of conclusions,"

- "reliance on toxicity ranges for agronomic plants," and

- "inconsistent conclusions."

He goes on to claim that effects from sulfur dioxide $\left(\mathrm{SO}_{2}\right)$ emissions entirely explain the current vegetation status. He further intimates that $\mathrm{Mt}$. Haggin has ample indigenous plant communities with sufficient regeneration.

He presents nine challenges to the upland restoration plan and concludes with a description of his own "Upland Plant Growth Study." Comments on the riparian area are presented under the response on STARS.

\subsection{Criticisms of State's Phytotoxicity Study}

The State used alfalfa, lettuce, and wheat as test species to evaluate phytotoxicity of soils from the impact area in a laboratory setting. These species have been used extensively in laboratory studies to evaluate phytotoxicity of site soils. Key considerations include repeatability of tests, availability of seeds, plus high percentage and rapid germination rates. The species represent major plant groups (grasses and forbs including a legume). Analysis of the data did establish a clear linkage between endpoints and contaminant concentrations and between endpoints and subsequently, current vegetation cover in the impact areas.

The modification Redente claimed invalidated the study was not a modification at all. Rather, it was a general caution regarding comparison of organic content of the soil. The selection of the reference area was done carefully with the objective of finding the most appropriate neighboring representation of what the impact areas should support given similar elevation, slope, and aspect. The reference area was not pristine, nor free from any of the major factors influencing the impact area (i.e., logging, grazing, fire, logging, or emissions). The difference between impact and reference areas was only in the magnitude of exposure to emissions. A consequence of this difference clearly affects the soil organic content. ${ }^{1}$

The State did provide a review of phytotoxic ranges presented in literature. However, it did not rely solely on those values to determine injury. The direct measures of phytotoxicity obtained in the laboratory study formed the basis for establishing the potential of phytotoxic effects; the field observations of contemporary conditions completed the critical linkage between hazardous substance release-potential toxic conditions-actual loss of vegetation to establish the magnitude of injury.

\footnotetext{
${ }^{1}$ In his report on Bunker Hill, Dr. Redente noted $\sim 2 \%$ soil organic matter from tree fragments that had not decomposed. If one were to apply a similar value here, the "true" soil organic content would be substantially less than the $5 \%$ target mentioned in ASTM. Fragments of wood are not part of the effective soil organic matter; rather the microscopic and near microscopic portions of decayed vegetation are what is of concern.
} 

The State did not hold that germination and survival is not possible. It did, however, conclude that phytotoxic conditions are likely to pose severe limitations on survival, which therefore accounts for the depauperate status of vegetation in the injured areas.

\subsubsection{Comments on Status of Upland Vegetation}

Dr. Redente attempts to describe all of the current vegetation injury pattern as a consequence of $\mathrm{SO}_{2}$ emissions and erosion effects, while discounting all phytotoxic properties of arsenic and metals. His claim that the State ignored $\mathrm{SO}_{2}$ is simply false. The State specifically considered $\mathrm{SO}_{2}$, as well as logging, grazing, fires, and the contaminants in question in its weight-of-evidence analysis. No mechanism for continued injury from $\mathrm{SO}_{2}$ has been described in the literature or in Dr. Redente's critique to account for the demonstrated phytotoxicity in soils currenlly on site or the depauperate vegetation. In fact, whereas the State considered all probable stressors and concluded that arsenic and metals alone account for the observed injury; Dr. Redente first argues that no injury has occurred, and then proceeds to claim that all the injury is entirely due to $\mathrm{SO}_{2}$ effects.

In his critique, Dr. Redente consistently fails to acknowledge that in its injury determination and its restoration plan, the State noted places within Stucky Ridge, Smelter Hill, and Mt. Haggin impact areas where stands of vegetation are present. Dr. Redente appears to want to extrapolate these relatively restricted places constituting a small percentage of the impacted area to be representative of the entire injured areas.

\subsection{Plant Growth Study}

\subsubsection{Description}

Dr. Redente claimed serious flaws existed in the State's phytotoxicity studies. He strongly criticized use of standardized species and discounted the importance of seedlings germinating and initiating growth in the top two inches of soil. He further claimed that the tests conducted were not consistent with the ASTM standard cited for the study.

The state clearly identified that the ASTM standard procedures were modified for the study. Moreover, the State described in detail what the substantive changes were. The general test conditions were described in the workplan, in subsequent reports, and finally detailed copies of laboratory Standard Operating Procedures for implementation of the test were provided during deposition.

In the State's phytotoxicity study, twenty soil samples (comprised of local composite samples as described in various reports) were tested individually. Endpoints were compared to values obtained from reference soils to determine statistically significant differences. The various soil samples-were collected at unbiased, randomly chosen locations. As such the samples provide a representative view of the area sampled, (i.e., sites having non-toxic soils are likely to be included in the sample in approximately the proportion that non-toxic samples occur within the area). The results of the State's tests did indeed contain some non-toxic samples as scored in the phytotoxicity tests.

Studies by PTI in the RI/FS phase of site work had demonstrated a strong vertical distribution pattern with substantially higher concentrations of contaminants at 0-2 inch depth than at 2-4 inch depth or 4-6 inch depth. Similar relationships were noted at the Bunker Hill, Idaho Superfund site, and other smelters. At Bunker Hill, plantings that penetrated below the top layer had a good likelihood of survival. The State's work on riparian zones had shown that diluting contaminated soils with equal quantities of clean soil alleviated phytotoxicity. Taking these data into account, the State proposed mixing the top two inches of soil with deeper less contaminated soil as an effective restoration activity.

Redente's greenhouse study used soils collected by Keammerer in 1994. The classification of sampling sites is described in Keammerer's report, but unfortunately is quite difficult to follow. Areas that Keammerer classified as grassland/forb were sampled in German Gulch, Stucky Ridge, and Mt. Haggin. Similarly, areas classified as barren were sampled in each area. Approximately equal numbers of samples (at $0-2$ inch depth and 2- inch depth)were obtained from each "vegetation typen with eight 

samples each taken in German Gulch, 25 samples from Stucky Ridge, and 33 samples from Mt. Haggin. Notably no soils were collected or tested from Smelter Hill! In addition to the Montana soils, Redente included a soil from the Fort Collins area as a reference.

Redente mixed the 0-2 inch soil samples from "grassed" and "barren" areas from each area. Similarly he mixed the 2-8 inch soil samples. He then prepared a tube with the mixed $2-8$ inch soil and layered the mixed 0-2 inch soil on top. In addition to the site soil, treatments of limed, fertilized, and limed plus fertilized were tested. Seeds of blue bunch wheat grass, slender wheat grass, and red top were planted in separate replicate tubes. Twelve seeds were placed in each replicate tube. These were later thinned to two plants per tube.

\subsubsection{Critique}

1. Blending soils from the "grassed" and "barren" areas (if indeed they represented "clean" versus "contaminated" soil), as already forecasted by the State in its reports and its restoration plan, should alleviate some of the phytotoxic conditions.

2. From a study design aspect, mixing of soils, as done by Redente, assumes an equal distribution of the two types would be representative of the entire area. The evidence produced by the State argues that the barren areas would be under-represented in Redente's study design. Therefore, the mixing does not produce a representative sample of the larger area.

3. Although Redente severely criticized the State for modifying the ASTM standard procedure, his study followed no published or referenced procedure, nor did it provide adequate description to evaluate what was done. None of the original data sheets, records, laboratory log books, descriptions of environmental conditions in the greenhouse, personnel involved in conducting the tests, or analyzing the results were provided. Several key issues needed for proper interpretation of the results were not addressed in the proposal, data sheets, or reports. These include:

- What criteria were used to select the two seedlings retained for the 13-week study?

- What variability in plant size existed at the time of thinning?

- Why were no measurements or observations taken prior to thinning?

4. The description of the study in Redente's report does not match all aspects of his proposal as referenced in RED000000528-530. Under the approach, Redente provides the following estimates of soil available for the study:

\begin{tabular}{|l|c|c|}
\hline \multicolumn{3}{|c|}{ Table 1. Soil available for Redente greenhouse study. } \\
\hline Location & $0-2$ inch depth (lbs) & $2-8$ inch depth (lbs) \\
\hline Stucky Ridge & 146 & 129 \\
\hline Mt. Haggin & 151 & 134 \\
\hline German Gulch & 16 & 14 \\
\hline
\end{tabular}

Since there should be approximately 3 -fold more soil from the lower depth, it is clear that collections were not made at all sample sites. This raises obvious questions about what was collected? He further states that "if adequate soil is available" five replicates would be used. Since the soil was already collected, it's not clear why there was a question.

5. With four replicates, Redente was restricted to making final statistical comparisons on eight investigator selected plants (i.e., two per pot if both survived). That is, seeds that did not germinate or which germinated late were apparently "thinned" out of the study. In the State's study, the results were based on 100 seeds with no human selection taking place. Redente's study had the effect of tracking the most resistant members of the population of seeds planted in each treatment even if uniform bias was exercised throughout the study. 

6. On page B-24 (Table 7), Redente reports the germination/emergence for the first four weeks of the study. In his various treatments (including the Ft. Collins soils) emergence for bluebunch wheat grass ranged from 33 to $100 \%$; slender wheatgrass ranged from 25 to $92 \%$; and red top ranged from 33 to $100 \%$. Emergence varied from week one through the fourth week. This presents substantial limitations on test procedures and confounds interpretation. Absent a documentation of what was done, and when, it becomes impossible to judge the validity of the test results.

7. The statistical analyses performed by Redente apparently included the combined variance of all treatments in his study design. This included plant growth in Ft. Collins soils that was substantially greater than any of the Montana soils. No justification for inclusion of the Ft. Collins soils was offered. In his analysis, Redente also included the data on plant growth in limed and fertilized Montana soils. Large variation due to substantially better growth in the Ft. Collins soils and the amended Montana soils masks differences that may have been observed in the unamended Montana soils alone.

8. Examining just the Montana unamended soils plant growth data from Redente's study reveals severe limitations of the power of the study design. For whatever reason, only one replicate pot of reference soil (i.e., two plants) was used in the tests with slender wheatgrass and red top. This leaves little opportunity for statistical comparisons. A t-test examining whether slender wheat grass shoot growth in Stucky Ridge or Mt. Haggin soils is different from 1.00; or red top growth in soils from the two areas is different from 1.78 seems to be the extent of comparison available. Similarly, tests of root and total plant growth could be attempted. A cursory look at the numbers suggests that both Stucky Ridge and Mt. Haggin supported less shoot, root, and total growth of slender wheatgrass than German Gulch soil. A similar comparison growth of red top appears to show less growth in shoots, roots, and total for Stucky Ridge, whereas Mt. Haggin shoot growth is not different from German Gulch, however, root growth and total growth are less in Mt. Haggin soil than in German Gulch.

The growth of bluebunch wheatgrass is difficult to evaluate since one of the four replicates (replicate 3 ) in the German Gulch soil had about one-order of magnitude less growth than the rest of the replicates. Root growth in German Gulch replicate 3 was similarly below par.

Tests of normality and homogeneity clearly indicate a need for transformation and or non-parametric analysis.

Table 2. Redente shoot growth (g) for German Gulch (GG), Stucky Ridge (SR), and Mt. Haggin (MH) soil samples.

$\left[\mathrm{BW}=\right.$ Bluebunch Wheatgrass; $S W=$ Slender Wheatgrass; $R T=$ Red Top $^{-}$

\begin{tabular}{|l|r|r|r|r|r|r|r|r|r|}
\hline Shoot & GG-BW & SR-BW & MH-BW & GG-SW & SR-SW & MH-SW & GG-RT & SR-RT & MH-RT \\
\hline rep-1 & 0.14 & 0.01 & 0.02 & 1.00 & 0.70 & 0.90 & 1.78 & 1.34 & 1.84 \\
\hline rep-2 & 0.21 & 0.02 & 0.04 & n.d. & 0.36 & 0.71 & n.d. & 1.00 & 1.99 \\
\hline rep-3 & 0.01 & 0.03 & 0.08 & n.d. & 0.69 & 0.83 & n.d. & 0.99 & 2.23 \\
\hline rep-4 & 0.49 & 0.01 & 0.09 & n.d. & 0.48 & 0.20 & n.d. & 1.59 & 2.18 \\
\hline Mean & 0.21 & 0.02 & 0.06 & 1.00 & 0.56 & 0.66 & 1.78 & 1.23 & 2.06 \\
\hline S.D. & 0.20 & 0.01 & 0.03 & n/a & 0.17 & 0.32 & n/a & 0.29 & 0.18 \\
\hline C.V & $95 \%$ & $55 \%$ & $57 \%$ & n/a & $30 \%$ & $48 \%$ & n/a & $24 \%$ & $9 \%$ \\
\hline
\end{tabular}





\begin{tabular}{|c|c|c|c|c|c|c|c|c|c|}
\hline Root & $\overline{\text { GG-BW }}$ & SR-BW & MH-BW & GG-SW & SR-SW & MH-SW & GG-RT & SR-RT & MH-RT \\
\hline rep-1 & 0.20 & 0.24 & 0.35 & 2.15 & 1.75 & 2.14 & 7.02 & 3.61 & 3.79 \\
\hline rep-2 & 0.96 & 0.44 & 0.66 & n.d. & 1.21 & 1.77 & n.d. & 3.03 & 4.61 \\
\hline rep-3 & 0.12 & 0.32 & 0.93 & n.d. & 1.82 & 1.92 & n.d. & 2.81 & 5.97 \\
\hline rep-4 & 1.12 & 0.09 & 1.22 & n.d. & 1.35 & 2.11 & n.d. & 4.30 & 5.22 \\
\hline Mean & 0.60 & 0.27 & 0.79 & 2.15 & 1.53 & 1.99 & 7.02 & 3.44 & 4.90 \\
\hline S.D. & 0.51 & 0.15 & 0.37 & $\mathrm{n} / \mathrm{a}$ & 0.30 & 0.17 & $\mathrm{n} / \mathrm{a}$ & 0.67 & 0.92 \\
\hline C.V. & $86 \%$ & $54 \%$ & $47 \%$ & $n / a$ & $19 \%$ & $9 \%$ & $n / a$ & $19 \%$ & $19 \%$ \\
\hline
\end{tabular}

\begin{tabular}{|c|c|c|c|}
\hline Test Species & Shoot & Root & Total \\
\hline \multicolumn{4}{|c|}{ Arsenic } \\
\hline Bluebunch Wheatgrass & -0.686 & 0.451 & 0.152 \\
\hline Slender Wheatgrass & -0.665 & -0.164 & -0.390 \\
\hline Redtop & 0.421 & -0.509 & -0.357 \\
\hline \multicolumn{4}{|c|}{ Copper } \\
\hline Bluebunch Wheatgrass & -0.796 & -0.840 & $-0.967^{\star}$ \\
\hline Slender Wheatgrass & -0.813 & $-0.998^{*}$ & $-0.957^{\star}$ \\
\hline Redtop & -0.858 & -0.910 & $-0.967^{*}$ \\
\hline
\end{tabular}





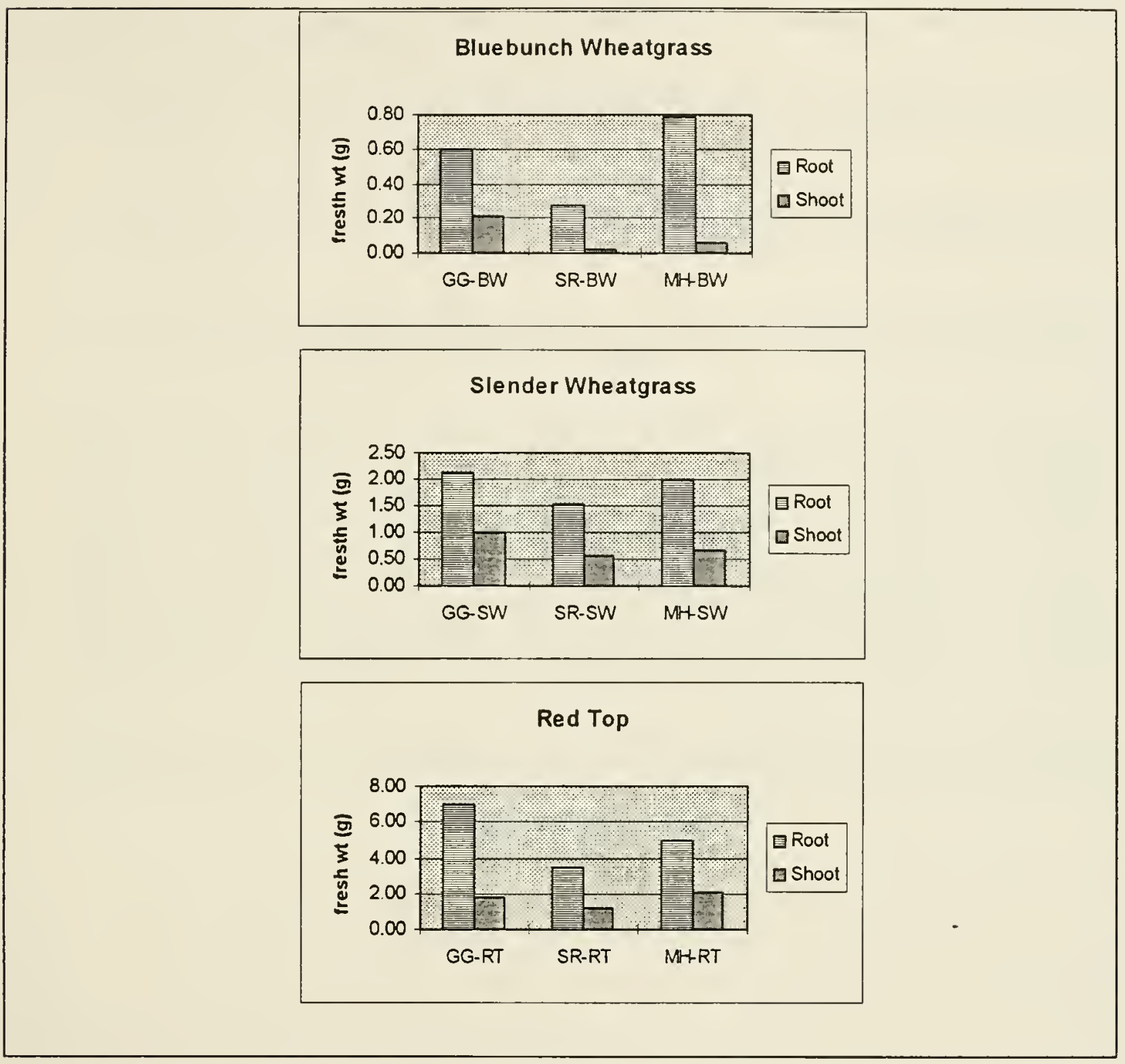

Figure 1. Average growth of three grasses in German Gulch (GG), Stucky Ridge (SR), and Mt. Haggin (MH) from Redente's study.

Focusing on the Montana soils, the relationship between plant growth and soil contamination in Redente's study links phytotoxic response to arsenic and copper concentrations. The following matrix of correlations was developed from the mean growth data and the soil concentration data taken from RED000000531 (Table 5). 

9. Though so few comparisons can be made from these data, several findings are consistent with the State's determination of phytotoxicity.

- Growth of all three grasses tested by Redente was less in Stucky Ridge soil for all three endpoints (i.e., root, shoot, and total). This is despite the blending of soils form vegetated and barren areas that predictably should lower the toxicity.

- Shoot growth in Mt. Haggin soil was less than shoot growth in German Gulch soil for bluebunch wheatgrass and slender wheatgrass. Root growth may be less in Mt. Haggin soil than in German Gulch soil.

- Total growth (shoot plus root) was reduced in Stucky Ridge and Mt. Haggin soils compared to German Gulch soil for both slender wheatgrass and red top. Total bluebunch wheatgrass growth was reduced in Stucky Ridge soil compared to German Gulch.

10. Redente goes on to claim that amending the Mt. Haggin and Stucky Ridge soils with lime and fertilizer "proves" that toxicity is not the limiting factor. However, his study design does not permit that ascertainment. Whereas it is apparently true that greater plant growth occurred in Mt. Haggin and Stucky Ridge soils when amended by either lime or fertilizer or both, and that the amount of plant growth approached that of the German Gulch soil, there is no comparable data provided regarding the effects of amending the German Gulch soil with lime or fertilizer or both. This is a "fortuitous omission" in study design. It is well known, that in almost all "natural" areas (here meaning non-fertilized agricultural soils), addition of fertilizers and if appropriate neutralizing soils will enhance plant growth for the short term (i.e., at least one growing season). Failure to include the full factorial design (i.e., amendments to German Gulch soils) eliminates all claims made by Redente regarding the causal differences.

11. The exclusion of Smelter Hill soil samples from the study design poses another curious situation. Since the State demonstrated phytotoxicity in this area, why did Redente choose to ignore this area in his study? 


